\title{
ENHANCED p53-DEPENDENT GROWTH INHIBITION OF HUMAN GLIOBLASTOMA CELLS BY COMBINATORIAL TREATMENT OF TEMOZOLOMIDE AND NOVEL PURIFIED NATURAL CARBOHYDRATE OF PLEUROTUS FLORIDA
}

\author{
PRIYANKAR MAJI ${ }^{{ }^{*}}$, RANODEEP CHATTERJEEb, SHIBANI BASUa, BISWA P. CHOUDHURYc, URMI CHATTERJI ${ }^{*}$, \\ JHUMA GANGULY $\mathrm{a}^{*}$
}

aDepartment of Chemistry, Indian Institute of Engineering Science and Technology, Shibpur, Howrah 711003, India, bCancer Research Laboratory, Department of Zoology, University of Calcutta, 35 Ballygunge Circular Road, Kolkata 700019, India, cGlycotechnology Core Resource, University of California, San Diego, La Jolla, CA-92093-0687, USA

Email: jhumaiiest@gmail.com

Received: 19 Feb 2017 Revised and Accepted: 09 May 2017

\section{ABSTRACT}

Objective: This study was designed to analyze the combinatorial chemotherapeutic effect of temozolomide (TMZ), the most common drug in glioblastoma treatment and a purified carbohydrate (Fr-II) from the edible mushroom Pleurotus florida, on human glioblastoma cell lines.

Methods: Fr-II was purified by size-exclusion chromatography and characterised by different mass spectroscopy analysis. Human glioblastoma cells were treated with TMZ, Fr-II, and combination of TMZ and Fr-II. Cell cytotoxicity was measured by MTT assay, cell cycle phase distribution was determined by cell cycle analysis and followed by the relative p 53 protein expression was analyzed by western blot analysis.

Results: Chemical analysis of Fr-II confirmed the glycosidically linked two units of glucose with terminally attached mannitol with mass of 506 Da Fr-II treatment exhibited cytotoxicity in both the cell lines in a dose-dependent manner with most effective dose at $200 \mu \mathrm{g} / \mathrm{ml}$. When Fr-II $(200 \mu \mathrm{g} / \mathrm{ml})$ was combined with a dose range of TMZ it showed a more cellular cytotoxicity compared to the cytotoxicity of TMZ alone with most oppressive combinatorial dose at $400 \mu \mathrm{M}(\mathrm{TMZ})+200 \mu \mathrm{g} / \mathrm{ml}$ (Fr-II). In compliance, with the above results, both cell lines showed a $10 \%$ increase in no. of cells $(\mathrm{p}<0.05)$ in $\mathrm{G}_{2} / \mathrm{M}$ phase indicating an arrest of cell cycle and increased p53 protein expression $(\mathrm{p}<0.05)$ at the combinatorial dose than TMZ alone at $400 \mu \mathrm{M}$, but Fr-II alone didn't show any cell cycle arrest nor did it show increased p53 expression.

Conclusion: Therefore it confirms that Fr-II synergizes with TMZ to significantly intensify its anti-proliferative properties, thereby emerging as an effective element for combinatorial treatment of glioblastoma.

Keywords: Glioblastoma, Combinatorial treatment, Edible mushroom, Cell cycle, Carbohydrate, p53

(C) 2017 The Authors. Published by Innovare Academic Sciences Pvt Ltd. This is an open access article under the CC BY license (http://creativecommons.org/licenses/by/4.0/) DOI: http://dx.doi.org/10.22159/ijpps.2017v9i6.18002

\section{INTRODUCTION}

Glioblastoma multiforme (GBM) is the most prevalent and aggressive form of primary brain tumors which demonstrates a high proliferation rate, an aggressive growth pattern and is mostly resistant to chemotherapy [1]. The infiltrative growth of glioma cells and their resistance to standard therapy have limited successful treatment, as a result of which the median survival of patients with GBM is approximately 12-15 mo [2]. Current GBM treatments include a combination of surgery, radiation, and chemotherapy, but these treatments can only offer palliative survival advantages. Thus, there is an urgent need for more effective treatment strategies which would ensure better prognosis of patients with brain tumors [3].

Currently, one of the most promising drugs for the treatment of brain tumor is Temozolomide (TMZ), an oral alkylating agent belonging to imidazotertrazines, which exhibits anti-cancer properties against malignancies [4]. TMZ is a small molecule compound with a molecular weight of $194 \mathrm{Da}$ and readily absorbed in the digestive tract. It is also able to cross the blood-brain barrier because of its lipophilicity. TMZ is extremely stable at the acidic $\mathrm{pH}$ of the stomach and is converted to the active form, 5-(3-methyltriazen-1-yl) imidazole-4-carboxamide (MTIC), when in contact with the slightly basic $\mathrm{pH}$ of the blood and tissues. Eventually, TMZ spontaneously undergoes hydrolysis to the active metabolite MTIC which rapidly breaks down to form the reactive methyl diazonium ion. The cytotoxicity of MTIC is due to the alkylation of DNA at the 06 and N7 positions of guanine [5,6], leading to the formation of 06methylguanine in DNA, which mispairs with thymine during DNA replication triggering futile cycles of the mismatch repair system and subsequently leads to DNA damage [7,8]. Further, 06-methylguanine lesions induced by alkylating agents activate the p53-controlled DNA damage response pathway. TMZ treatment is also known to result in $\mathrm{G}_{2} / \mathrm{M}$ phase arrest in some cancer cells [9-11]. According to Uzzaman et al., the average survival of patients with glioblastoma after TMZ treatment is $22 \mathrm{mo}$, which has not rendered the drug entirely satisfactory for therapy [12].

Possible reasons for limitation of chemotherapeutic approaches are several physiologic constraints. For example, TMZ which degrades to MTIC in the blood stream turns out to be limiting for treatment as MTIC is not absorbed readily by cells [13]. Novel drug delivery systems could, therefore, circumvent the conversion of TMZ and maintain the stability of the inactive molecular configuration till it has targeted the glioblastoma cells. There are several factors that influence drug access to the central nervous system (CNS): size of the molecule, lipophilicity, integrity of the blood-brain barrier that is typically damaged by the invasive GBM and finally, the presence of active drug efflux pumps [13]. Hypoxic tumor environment is yet another factor which makes GBM resistant to chemotherapy. Moreover, several patients with CNS tumors receive concomitant medications such as steroids and anti-epileptic drugs which may contribute to the reduced efficacy of the chemotherapeutics and potentially exacerbate their side effects. Thus, one of the most challenging problems in the therapy of GBM is its extremely complex and heterogeneous manifestation. Although TMZ is potentially beneficial and popularly used, there is still a substantial need for improvement of the drug and its delivery specifically to tumor cells. In accordance, effective combinatorial treatment strategies may ensure the enhanced efficacy of TMZ in brain tumors [14].

Since carbohydrate-based small molecule, oligosaccharides or glycoconjugates can leverage the challenges of absorption [15], they 
may augment the efficacy of the TMZ in combinatorial chemotherapy. As mushrooms are one of the richest diversified sources of bioactive carbohydrates possess immunomodulatory, free radical scavenging, anti-tumour and anti-cancer activities [16-21, 31, 32]. Currently, there is renewed interest in using mushrooms which were used as traditional medicines, and re-establishing their medicinal properties. Oyster mushroom (Pleurotus sp.) belongs to the family Tricholomataceae and has about 40 well-recognized species, out of which 12 species are cultivated in different parts of India [22]. In particular, P. florida possesses some bioactive carbohydrate with significant antioxidant and anti-tumour properties [23-24] and thereby promises to be of interest as a prospective anti-cancer drug for combinatorial chemotherapeutic.

The aim of this study was, therefore, to screen the combinatorial effect of mushroom carbohydrate from P. florida along with TMZ on human glioblastoma cell lines, U373 and U87MG.

\section{MATERIALS AND METHODS}

\section{Chemicals}

Temozolomide (Temoside ${ }^{\circledR} 100 \mathrm{mg}$, Cipla, Mumbai, India), sephadex G-50, trifluroacetic acid, isopropanol, acetic anhydride, tri-sil reagent (Thermo Scientific, USA), thiazolyl blue tetrazolium bromide (MTT), triton X-100, sodium chloride, sodium dodecyl sulphate, Tris, protease inhibitor cocktail and propidium iodide (SigmaAldrich ${ }^{\circledR}$ USA) and RNase A (Genei ${ }^{\circledR}$, India), p53 antibody, $\beta$-tubulin antibody, anti-mouse enhanced chemiluminescence (ECL) kit (Abcam) and Dulbecco's modified eagle media (DMEM), minimal essential media (MEM), fetal bovine serum (FBS) and penicillinstreptomycin antibiotic cocktail(HiMedia ${ }^{\circledR}$, India).

\section{Cell lines}

Human glioblastoma cell line U373 was a kind donation from Dr Chitra Mondal, Indian Institute of Chemical Biology (Kolkata, India) and U87MG was purchased from National Centre for Cell Science (Pune, India).

\section{Apparatus}

HPEAC-PAD was performed by Dionex ICS 3000 HPLC system, GCMS was performed by Agilent 5820A GC system equipped with 5975 Series MSD detector, Mass was analyzed by MALDI-TOF (Bruker Daltronics) and flow cytometry was analyzed in C6 BD Accuri (BD Biosciences, USA).

\section{Plant material}

The compound was isolated and purified from the fruiting body of Pleurotus florida cultivar Assam Florida. Pleurotus florida cultivar Assam Florida, mushrooms were collected from a mushroom farm in North Bengal with $26.6835^{\circ} \mathrm{N}, 88.7689^{\circ} \mathrm{E}$ (West Bengal, India) in dried conditions. And the mushroom had produced using characterised seed obtained from Tamil Nadu Agricultural University, Coimbatore, India and maintained to produce fruiting body well-defined culture media and methods.

\section{Preparation of aqueous extract of mushrooms}

The dried mushrooms were ground to produce the mushroom powder which was used as the source material for water extraction. Briefly, the mushroom powder $(10 \mathrm{gm})$ was soaked in $300 \mathrm{ml}$ of deionized water and kept in stirring condition overnight followed by extraction for $3 \mathrm{~h}$ at $50{ }^{\circ} \mathrm{C} \pm 5{ }^{\circ} \mathrm{C}$. The extract was centrifuged at $10,000 \mathrm{rpm}$ for $20 \mathrm{~min}$ at $20^{\circ} \mathrm{C}$ and the supernatant was collected by filtration through a linen cloth, freeze-dried and used for further experiments.

\section{Purification of carbohydrate-enriched fractions}

The supernatant was purified by gel permeation chromatography using Sephadex G-50 column (100 cm x $1.5 \mathrm{~cm})$ and water as eluant. Each fraction was monitored for the estimation of neutral carbohydrates using phenol-sulphuric acid assay method [25]. There were two major (baseline separated) carbohydrate-rich fractions separated and designated as Fr-I and Fr-II. These fractions were freeze-dried and used for further chemical analysis and experiments. Only Fr-II was used for the further studies.
Preparation of the sample for high-performance anionexchange chromatography Pulse amperometric detection (HPAEC-PAD) for monosaccharide analysis

Fr-II fraction $(200 \mu \mathrm{g})$ was dissolved in $1 \mathrm{ml}$ water and $100 \mu \mathrm{l}$ was taken for monosaccharide composition analysis. Briefly, samples were hydrolysed using $2(\mathrm{~N})$ tri-fluroacetic acid (TFA) at $100^{\circ} \mathrm{C}$ for $6 \mathrm{~h}$. After hydrolysis, the acid was removed by dry nitrogen flush and co-evaporated with $50 \%$ isopropanol $(100 \mu \mathrm{l})$ twice to ensure complete removal of acid. Finally, the hydrolyzed samples were dissolved in $1 \mathrm{ml}$ of deionized water and $100 \mu \mathrm{l}$ was injected on the column of Dionex ICS 3000 HPLC system equipped with CarboPac ${ }^{\circledR}$ PA-1 column ( 4 x $250 \mathrm{~mm}$ ). A buffer gradient of $100 \mathrm{mMNaOH}$ with $250 \mathrm{mMNaOAc}$ was used to obtain a good baseline resolution of monosaccharides. Monosaccharides in samples were identified and quantified using the mixture of $1 \mathrm{nM}$ authentic known monosaccharide standards [26].

\section{GC-MS analysis for molecular ratio analysis of monosaccharides}

Mannitol and monosaccharides were further confirmed by GC-MS of trimethylsilyl (TMS) derivatization of the active fraction [27]. Finally, the TMS derivative of Fr-II and standard reference samples were dissolved in Hexane and GC-MS analysis was performed using Agilent 5820A GC system equipped with 5975 Series MSD detector. Gas chromatography separations of the monosaccharides were performed using Restek $5 \mathrm{~ms}$ column $(30 \mathrm{~m} \times 0.25 \mathrm{~mm} \times 0.25 \mu \mathrm{m})$ and detection was done on $70 \mathrm{eV}$ positive EI mode. Helium was used as carrier gas and the analysis was done using splitless mode.

\section{Per-0-methylation analysis (PM) of glycan}

Linkage analysis was performed on purified Fr-II by GC-MS of per-Omethylated alditol acetate (PMAA) derivative [27]. PMAA analysis was done byGC-MS using Restek-5ms capillary column (30m x0.25 $\mathrm{mm}$ ). Identification was achieved by using a combination of retention times (as compared to those of known standards analyzed under the same conditions) and mass fragmentation pattern.

Oven temperature gradient: $120{ }^{\circ} \mathrm{C}-3{ }^{\circ} \mathrm{C} / \mathrm{min}-180{ }^{\circ} \mathrm{C}-1$ min-5 ${ }^{\circ} \mathrm{C} / \mathrm{min}-230-14 \mathrm{~min}$; Injector temp: $220{ }^{\circ} \mathrm{C}$; Mass transfer line temp: $280^{\circ} \mathrm{C}$, He gas flow: $1.4 \mathrm{ml} / \mathrm{min}$.

\section{Mass analysis by MALDI-TOF}

The molecular mass of the Fr-II was performed by MALDI-TOF (Bruker Daltronics) using 2,5-dihydroxybenzoic acid(DHB) as the matrix. 1 $\mathrm{mg} / \mathrm{ml} \mathrm{sample} \mathrm{was} \mathrm{mixed} \mathrm{with} \mathrm{saturated} \mathrm{DHB} \mathrm{in} \mathrm{1:1} \mathrm{ratio} \mathrm{and} \mathrm{subjected}$ to analysis for mass fragmentation by MALDI [27]. The data was interpreted using Bruker Daltronics flex analysis ${ }^{\circledR}$ software.

\section{Cell culture}

U373 cells were cultured in Dulbecco's Modified Eagle Medium (DMEM) and U87MG in Eagle's Minimal Essential Medium (MEM)supplemented with $10 \%$ fetal bovine serum and $1 \%$ penicillinstreptomycin and grown in $5 \% \mathrm{CO}_{2}$ and $37{ }^{\circ} \mathrm{C}$ conditions. Confluent cultures were detached with trypsin and subcultured every $72 \mathrm{~h}$.

\section{Cytotoxicity assay}

The effects of Fr-II (25, 50, 100, $200 \mu \mathrm{g} / \mathrm{ml})$, TMZ (25, 50, 100, 200 and $400 \mu \mathrm{M})$ and TMZ combined with Fr-II $(200 \mu \mathrm{g} / \mathrm{ml})$ were studied on the viability of glioblastoma cell lines after $72 \mathrm{~h}$ of treatment. Cells were seeded in 96-well plates and grown for $22 \mathrm{~h}$. Cell viability was measured by a quantitative colorimetric assay using MTT according to the manufacturers' instructions [28]. The data was expressed as a percentage of control. The dose/concentration selected was used for subsequent experiments.

\section{Flow cytometric analysis}

Around $3 \times 10^{5}$ cells were plated onto 6-well culture dishes and treated with $400 \mu \mathrm{M} \mathrm{TMZ}$ and $200 \mu \mathrm{g} / \mathrm{ml} \mathrm{Fr-II} \mathrm{for} 72 \mathrm{~h}$. At the end of treatment, cells were washed with cold PBS ( $\mathrm{pH}$ 7.4), re suspended in hypotonic sodium citrate buffer with triton-X $100(0.1 \%)$, RNase A $(50 \mu \mathrm{g} / \mathrm{ml})$ and propidium iodide (PI, $100 \mu \mathrm{g} / \mathrm{ml})$ and incubated for $15 \mathrm{~min}$ [29]. Cells were subjected to flow cytometric analysis in a BD Accuri C6 and data quantified using the C6 software 


\section{Western blot analysis}

Cells were lysed in ice-cold RIPA Buffer $(150 \mathrm{mMNaCl}, 50 \mathrm{~mm}$ Tris, $0.1 \%$ Triton X-100 and $0.1 \%$ SDS containing protease inhibitors An equal amount of proteins were fractioned by 10\% SDS-PAGE, transferred to PVDF membranes and blocked with 5\% non-fat milk. Blots were subsequently incubated with p53 antibody for $18 \mathrm{~h}$ at 4 ${ }^{\circ} \mathrm{C}$. $\beta$-tubulin antibody $(1: 1000)$ was used as a loading control. Blots were subsequently incubated with HRP-conjugated goat anti-mouse IgG secondary antibodies for $2 \mathrm{~h}$ at $25{ }^{\circ} \mathrm{C}$ [30]. Immunoreactive proteins were detected by incubating the membranes in ECL kit for 2 min* and quantified using the ImageLab ${ }^{\circledR}$ software.

\section{RESULTS}

\section{Chemical analysis of Fr-II by HPAEC-PAD and GC-MS}

The HPAEC-PAD analysis of the TFA hydrolyzed product of Fr-II showed the presence of glucose as major monosaccharide. Further GC-MS analysis of TMS derivatives of Fr-II showed glucose and mannitol in a molar ratio of $2: 1$. GC-MS analyses for the partially

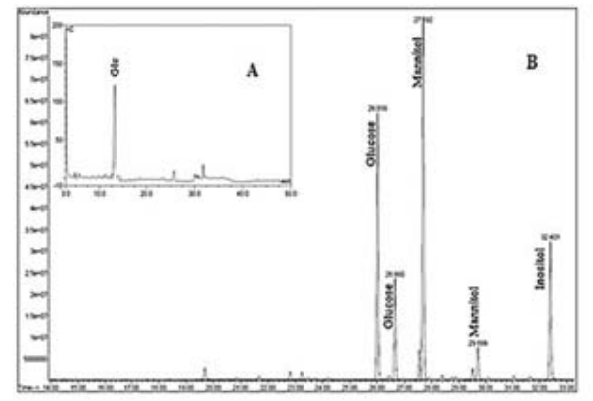

methylated alditol acetates of Fr-II revealed the presence of (i)1,5di-O-acetyl-2,3,4,6-tetra-0-methyl-D-glucitol (ii) 1,5,6-tri-0-acetyl2,3,4 tri-0-methyl-D-glucitol and (iii) 1,4,5-tri-0-acetyl 2,3,6 tri-Omethyl-glucitol and (iv) terminal mannitol. These results indicate

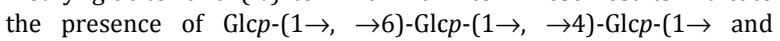
Mannitol $(1 \rightarrow)$. The mass analysis of Fr-II by MALDI-TOF showed the peak of 551Da which was actually the precursor of the mass of $506 \mathrm{Da}$ of Fr-II $\left(\left[\mathrm{M}-\mathrm{H}^{+}+2 \mathrm{Na}\right]=551\right)$. The analysis of MALDI and permethylated GCMS confirm the presence two possible structures having glucose and mannitol (fig. 1).

\section{Cytotoxicity and cell viability assay}

Both U373 and U87MG cells showed a significant reduction in viability of the cancer cells as shown by MTT assay. When treated with Fr-II, cells show $\sim 50 \%$ cell survivability at a concentration $200 \mu \mathrm{g} / \mathrm{ml}$ when compared to the control (fig. 2A). Treatment with TMZ indicated the highest mortality at $400 \mu \mathrm{M}$ (fig. 2B). However, when TMZ was combined with $200 \mu \mathrm{g} / \mathrm{ml}$ Fr-II it exhibited significantly enhanced reduction in cell viability when compared to TMZ alone (fig. 2C).

Fig. 1: Chemical analysis of Fr-II. HPAEC-PAD chromatogram (A) and GC-MS of TMS-derivative of Fr-II (B), where inositol used as internal standard. (C) The structure of Fr-II proposed two units of glucose linked either by $1 \rightarrow 6$ glycosidic linkage (I) or $1 \rightarrow 4$ glycosidic linkage (II) between the units, while mannitol was attached to the moiety. Mass fragmentation pattern by MALDI confirmed a molecular mass of $506 \mathrm{Da}$

A

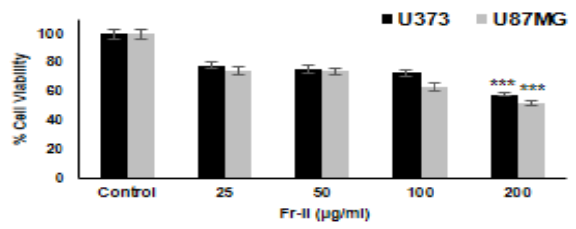

B

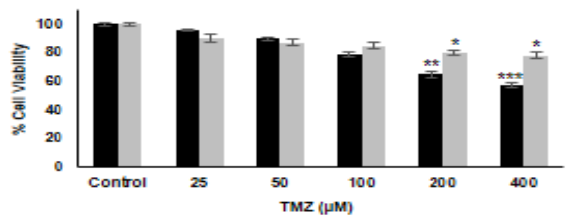

$\mathrm{C}$

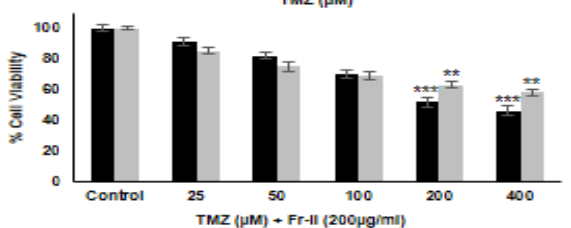

Fig. 2: MTT assay of glioblastoma cells treated without and with TMZ, Fr-II and a combination of TMZ and Fr-II. (A) The graph represents \% cell viability of U373 and U87MG cells when treated with Fr-II $(25,50,100$ and $200 \mu \mathrm{g} / \mathrm{ml})$. Both the cell lines show $\sim 50 \%$ cell survivability at a concentration of $200 \mu \mathrm{g} / \mathrm{ml}$. (B) Graph represents \% cell survivability of U373 and U87MG cells treated with TMZ $(25,50,100,200$ and $400 \mu M)$ (C) Histogram represents \% cell survivability of U373 and U87MG cells treated with varying concentrations of TMZ $(25,50,100,200$ and $400 \mu \mathrm{M})$ and $200 \mu \mathrm{g} / \mathrm{ml}$ of Fr-II. Values are represented as mean $\pm S D, n=3,{ }^{* *} p<0.01,{ }^{* * *} p<0.001$ with respect to their corresponding controls in each case

Therefore, when administered together, an additive effect was observed indicating enhanced cellular toxicity of the drug when delivered as a combination in contrast to the drug alone. The results are representative of three individual experiments in comparison to that of control experiments and p-value determined by student's ttest in all cases.

\section{Cell cycle analysis}

Human glioblastoma cells were treated with or without $400 \mu \mathrm{m}$ TMZ AND $200 \mu \mathrm{g} / \mathrm{ml}$ of Fr-II. The percentage of cells in different phases of the cell cycle were assessed and documented. Although Fr-II was cytotoxic to cells, interestingly it had no effect on the distribution of cells in different phases of the cell cycle, whereas TMZ significantly reduced cells in the $G_{1}$ phase of the cell cycle and increased cells in the $\mathrm{G}_{2} / \mathrm{M}$ phase. Interestingly, when administered together, the drug led to enhanced the arrest of cells in the $\mathrm{G}_{2} / \mathrm{M}$ phase of the cell cycle $(\mathrm{p}<0.05)$ determined by student's T-Test in both cell lines (fig. 3 ).

\section{Expression of p53}

Since the glioblastoma cell lines had different p53 status, the expression of p53 protein was determined after treatment with TMZ and Fr-II. Analysis revealed that Fr-II alone did not significantly change the expression of p53, when compared to the control, in U87MG cells, whereas a combination of Fr-II and TMZ shows relatively higher expression of p53 (p<0.05) determined by student's t-test when compared to TMZ alone (fig. 4). A similar pattern was observed in U373 cells, where the combination of compound and TMZ showed higher expression of p53 $(\mathrm{p}<0.05)$ determined by student's t-test, compared to TMZ alone (fig. 4). 
A

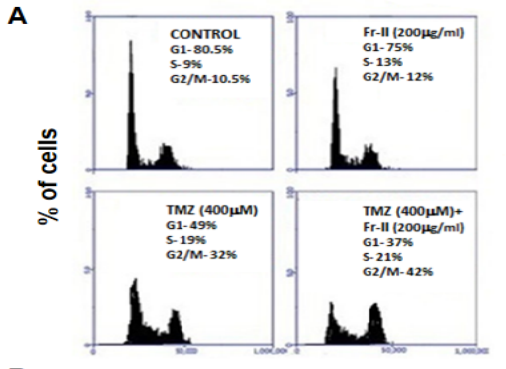

B

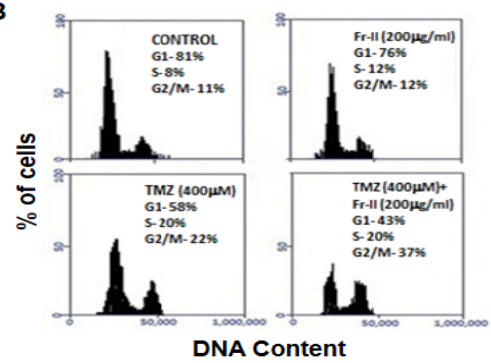

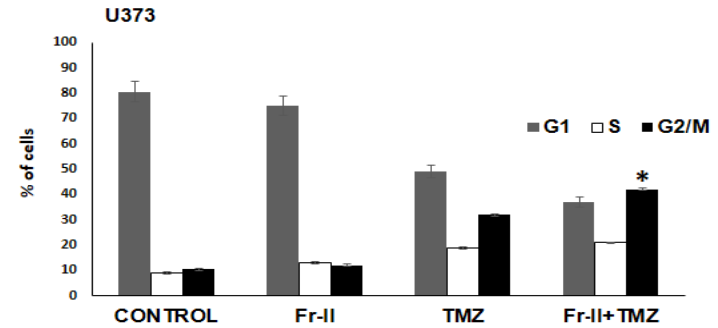

U87MG

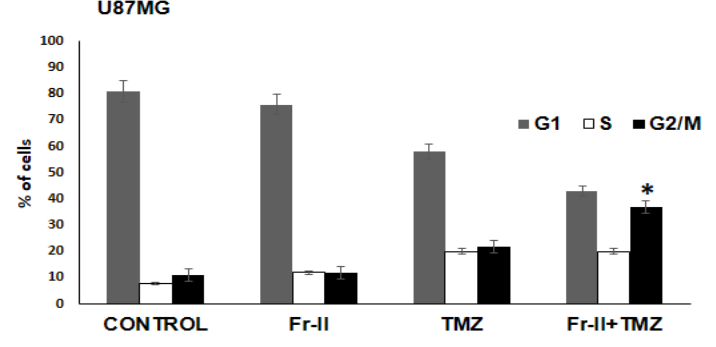

Fig. 3: Cell cycle assay of glioblastoma cells treated with a combination of TMZ and Fr-II. (A) Flow cytometric analysis showing the distribution of U373 cells treated with Fr-II $(200 \mu \mathrm{g} / \mathrm{ml})$, TMZ $(400 \mu \mathrm{M})$, and the combination of TMZ and Fr-II. An increase in G2/M

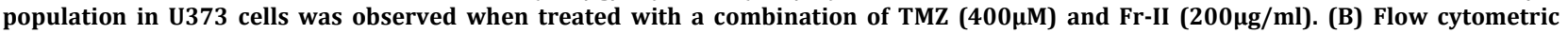
analysis showing the distribution of U87MG cells treated with Fr-II $(200 \mu \mathrm{g} / \mathrm{ml})$, TMZ $(400 \mu \mathrm{M})$, and the combination of TMZ and Fr-II. An increase $\mathrm{G}_{2}$ /M population of U87MG cells was observed when cells were treated with a combination of TMZ and Fr-II as compared to TMZ treatment alone. Values are represented as mean $\pm S D, n=3,{ }^{*} p<0.05$ with respect to $G_{2} / M$ phase of only $T M Z$ treated cells in each case
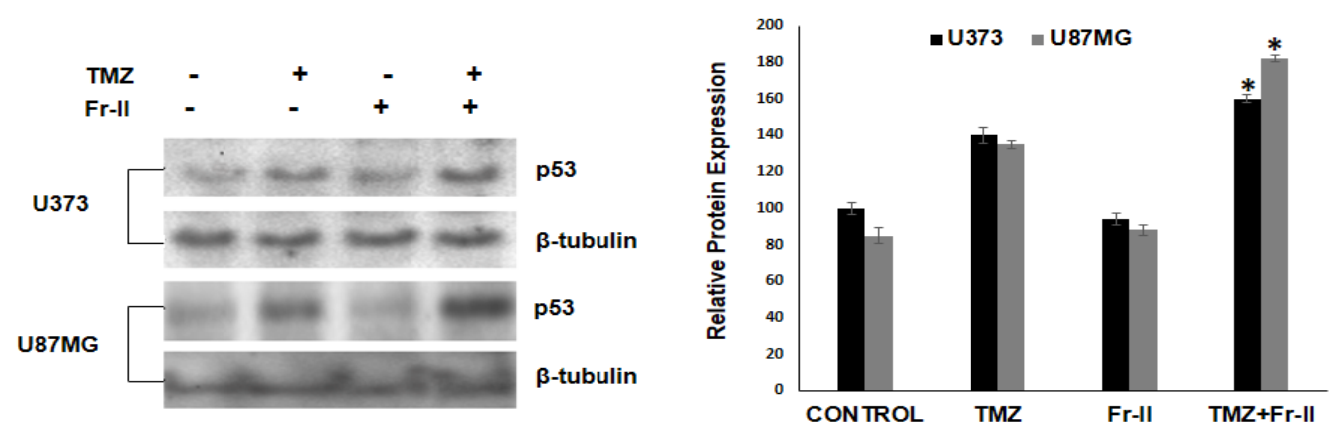

Fig. 4: Expression of p53 in glioblastoma cells. The expressions of p53 by TMZ, Fr-II, and combination of both TMZ and Fr-II were determined in U373 and U87MG cells. Relative protein expression indicated an enhanced expression when cells were treated with the combination of TMZ and Fr-II. Values are represented as mean \pm SD, $n=3,{ }^{*} \mathbf{p}<0.5$ with respect to p53 expression of only TMZ treated cells in each case

\section{DISCUSSION}

Our study indicated that TMZ, a well-known anti-cancer drug known to show cancer cell cytotoxicity and G2/M arrest $[4,10]$. Mechanism of action of TMZ is that it causes 06-methylguanine lesions which in turn activates the p53-controlled DNA damage response pathway [511, 31]. These properties are hiehtened when Fr-II from P. florida, results showed enhanced cellular cytotoxicity and led to a significant $(p<0.05) G_{2} / M$ arrest in the cell cycle when compared to the effects of TMZ alone. Furthermore, the action of TMZ which causes 06methylguanine lesions to activate the p53-controlled DNA damage response pathway was also heightened $(\mathrm{p}<0.05)$ when TMZ was combined with Fr-II as determined by their relative p53 expression. In addition, the Fr-II, which by itself did not have anti-proliferative properties, but was successful in enhancing the efficacy of TMZ. Although the exact mechanism of this action is still unknown, we hypothesize water-soluble purified carbohydrate (Fr-II) from the $P$. florida enhanced the anti-proliferative properties of TMZ by facilitating the influx of the drug into the cell as both mannitol and glucose, the major constituents of Fr-II, have excellent cell permeability properties [15]. Secondarily, Fr-II may act by improving the access and half-life of TMZ which could promote a greater accumulation of TMZ within cells. This permeation could enhance drug uptake capability of cells which eventually exhibit enhanced therapeutic impact. The drug would, therefore, be more effective and lower doses could be utilized in current therapeutic management strategies. This would render treatment of glioblastomas less expensive and more efficient, with reduced sideeffects, thereby improving prognosis. Extensive studies, however, needs to be carried out in vivo to validate the combined antiproliferative efficacy of TMZ and Fr-II prior to phase trials.

\section{CONCLUSION}

To best of our knowledge, we are the first to demonstrate that the combination of naturally occurring purified carbohydrates from $P$. florida and TMZ increases the efficacy of the drug by enhancing its anti-cancer properties, such as cellular cytotoxicity, cell cycle arrest and higher expression of p53 significantly in Glioblastoma cell lines. As both mannitol and glucose have excellent cell permeability properties, improving the access and half-life of TMZ would promote a greater accumulation of TMZ within cells. Such permeation could 
enhance drug uptake capability of cells which eventually exhibit enhanced therapeutic impact. The drug would, therefore, be more effective and lower doses could be utilized in current therapeutic management strategies. This would render treatment of glioblastomas less expensive and more efficient, with reduced sideeffects, thereby improving prognosis. Extensive studies, however, need to be carried out in vivo to validate the combined antiproliferative efficacy of TMZ and Fr-II prior to phase trials.

\section{ACKNOWLEDGEMENT}

We are sincerely acknowledged Mr. Dibyendu Mazumder for his kind support by providing the mushrooms for this study. We are also indebted to Department of Biotechnology, Govt. of India, for all financial support (Ref No: BT/PR6195/FNS/20/648/2012) and University Grant Commission, Govt. of India [F. No.41-325/ 2012(SR)] for fellowship for PM.

\section{AUTHORS CONTRIBUTION}

PM, RC, UC and JG were designed the experiments, studies and writing the manuscript. PM and RC performed the experiment and analysis and data interpretation. BPC performed the HPEAC-PAD and GCMS analysis.

\section{CONFLICT OF INTERESTS}

The authors don't have any conflict of interest

\section{REFERENCES}

1. Brada M, Hoang-Xuan K, Rampling R, Dietrich PY, Dirix LY, Macdonald D, et al. Multicenter phase II trial of temozolomide in patients with glioblastoma multiforme at first relapse. Ann Oncol 2001;12:259-66.

2. Zhang J, Stevens MF, Bradshaw TD. Temozolomide: mechanisms of action, repair and resistance. Curr Mol Pharmacol 2012;5:102-14.

3. Huse JT, Holland EC. Targeting brain cancer: advances in the molecular pathology of malignant glioma and medulloblastoma. Nat Rev Cancer 2010;10:319-31.

4. Marchesi F, Turriziani M, Tortorelli G, Avvisati G, Torino F, De Vecchis L. Triazene compounds: mechanism of action and related DNA repair systems. Pharmacol Res 2007;56:275-87.

5. Agarwala SS, Kirkwood JM. Temozolomide, a novel alkylating agent with activity in the central nervous system, may improve the treatment of advanced metastatic melanoma. Oncologist 2000;5:144-51.

6. Yin LT, Fu YJ, Xu QL, Yang J, Liu ZL, Liang AH, et al. Potential biochemical therapy of glioma cancer. Biochem Biophys Res Commun 2007;362:225-9.

7. Katayama M, Kawaguchi T, Berger MS, Pieper RO. DNA damaging agent-induced autophagy produces a cytoprotective adenosine triphosphate surge in malignant glioma cells. Cell Death Differ 2007;14:548-58.

8. Kim JT, Kim JS, Ko KW, Kong DS, Kang CM, Kim MH, et al. Metronomic treatment of temozolomide inhibits tumor cell growth through reduction of angiogenesis and augmentation of apoptosis in orthotopic models of gliomas. Oncol Rep 2006;16:33-9.

9. Hickman MJ, Samson LD. Apoptotic signalling in response to a single type of DNA lesion, 06-methylguanine. Mol Cell 2004;14:105-16.

10. Hirose Y, Berger MS, Pieper R0. p53 effects both the duration of $\mathrm{G} 2 / \mathrm{M}$ arrest and the fate of temozolomide-treated human glioblastoma cells. Cancer Res 2001;61:1957-63.

11. Mhaidat NM, Zhang XD, Allen J, Avery-Kiejda KA, Scott RJ, Hersey P. Temozolomide induces senescence but not apoptosis in human melanoma cells. Br J Cancer 2007;97:1225-33.

12. Uzzaman M, Keller G, Germano IM. Enhanced proapoptotic effects of tumor necrosis factor-related apoptosis-inducing ligand on temozolomide-resistant glioma cells. J Neurosurg 2007;106:646-51.

13. Meer L, Janzer RC, Kleihues P, Kolar GF. In vivo metabolism and reaction with DNA of the cytostatic agent 5-(3,3-dimethyl-1triazeno)imidazole-4-carboxamide (DTIC). Biochem Pharmacol 1986;35:3243-7.
14. Mrugala M. Advances and challenges in the treatment of glioblastoma: a clinician's perspective. Discovery Med 2013;15:221-30.

15. Davis BG, Robinson MA. Drug delivery systems based on sugarmacromolecule conjugates. Curr Opin Drug Discovery Dev 2002;5:279-88.

16. Cheung PCK. Mini-review on edible mushrooms as a source of dietary fiber: Preparation and health benefits. Food Sci Human Wellness 2013;2:162-6.

17. Valverde ME, Hernández-Pérez T, Paredes-López O. Edible mushrooms: improving human health and promoting quality life. Int J Microbiol 2015;376-8. Doi:10.1155/2015/376387.

18. Moradali MF, Mostafavi H, Ghods S, Hedjaroude GA. Immunomodulating and anticancer agents in the realm of micromycetes fungi (macrofungi). Int J Immunopharmacol 2007;7:701-24.

19. Chen Y, Xie MY, Nie SP, Li C, Wang YX. Purification, composition analysis and antioxidant activity of a polysaccharide from the fruiting bodies of Ganoderma atrum. Food Chem 2008;107:231-41.

20. Kishida E, Sone Y, Misaki A. Effects of branch distribution and chemical modifications of antitumor $(1 \rightarrow 3)-\beta$-d-glucans. Carbohydr Polym 1992;17:89-95.

21. Dey B, Bhunia SK, Maity KK, Patra S, Mandal S, Maiti S, et al. Chemical analysis of an immune-enhancing water-soluble polysaccharide of an edible mushroom, Pleurotus florida blue variant. Carbohydrate Res 2010;345:2736-41.

22. Rout D, Mondal S, Chakraborty I, Pramanik M, Islam SS, Structural characterisation of an immunomodulating polysaccharide isolated from an aqueous extract of Pleurotus florida fruit-bodies. Med Chem Res 2004;13:509-17.

23. Ahmed SA, Kadam JA, Mane VP, Patil SS, Baig MMV. Biological efficiency and nutritional contents of Pleurotus florida (Mont.) singer cultivated on different agro-wastes. Nat Sci 2009;7:44-8.

24. Jose N, Janardhanan KK. Antioxidant and antitumor activity of Pleurotus florida. Curr Sci 2000;79:941-3.

25. DuBois M, Gilles KA, Hamilton JK, Rebers PA, Smith F. Colorimetric method for determination of sugars and related substances. Anal Chem 1956;28:350-6.

26. Khatua B, Vleet JV, Choudhury BP, Chaudhry R, Mandal C. Sialylation of outer membrane porin protein D: a mechanistic basis of antibiotic uptake in Pseudomonas aeruginosa. Mol Cell Proteomics 2014;13:1412-28.

27. Ogata S, Shimizu C, Franco A, Touma R, Kanegaye JT, Choudhury BP, et al. Treatment response in Kawasaki disease is associated with sialylation levels of endogenous but not therapeutic intravenous immunoglobulin G. PLoS One 2013;8:e81448.

28. Kumar S, Acharya R, Chatterji U, De P. Controlled synthesis of $\beta$ sheet polymers based on side-chain amyloidogenic short peptide segments via RAFT polymerization. Polymer Chem 2014;5:6039-50.

29. Roy P, Das S, Mondal A, Chatterji U, Mukherjee A. Nanoparticle engineering enhances anticancer efficacy of andrographolide in MCF-7 cells and mice bearing EAC. Curr Pharma Biotech 2012;13:2669-81.

30. Chatterjee A, Chatterji U. Arsenic abrogates the estrogensignaling pathway in the rat uterus. Reprod Biol Endocrin 2010;8:80.

31. Vogelstein B, Lane D, Levine AJ. Surfing the p53 network. Nature 2000;408:307-10.

32. Saka S, Singh An, Sharma N. Potential anti-cancer superfoods: a minireview. Int J Curr Pharm Res 2016;8:19-21.

33. Hafeez Aa, Rakha Om. Paederus Alfieri extract induces apoptosis in human myeloid leukemia K562 cells. Asian J Pharm Clin Res 2017;10:72-5.

\section{How to cite this article}

- $\quad$ Priyankar Maji, Ranodeep Chatterjee, Biswa P Choudhury, Urmi Chatterji, Jhuma Ganguly. Enhanced p53-dependent growth inhibition of human glioblastoma cells by combinatorial treatment of temozolomide and novel purified natural carbohydrate of pleurotus florida. Int J Pharm Pharm Sci 2017;9(6):189-193. 